\title{
Modelo de jogo e processo de ensino no futebol: princípios globais e específicos
}

\author{
Rodrigo Vicenzi Casarin ${ }^{*}$ \\ Riller Silva Reverdito ${ }^{* *}$ \\ Dênis de Lima Greboggy*** \\ Carlos Alberto Afonso***** \\ Alcides José Scaglia ${ }^{* * * * *}$
}

\begin{abstract}
Resumo: A dimensão tática deve ser entendida como centro do processo de ensino-aprendizagem no futebol, assumindo seu caráter organizativo, multidimensional, intencional e consciente. Este artigo teve como foco, apresentar conceitos e conteúdos para sustentação de um processo de ensinoaprendizagem, baseado na dimensão tática e na interdependência de três aspectos fundamentais: metodologia para compreensão tática, princípios de jogo e modelos de jogo. Foram sugeridos e descritos em específico, princípios e modelos de jogo direcionados para diferentes faixas etárias, sendo estes compostos por peculiaridades comuns aos jogos esportivos coletivos de invasão.
\end{abstract}

Palavras chaves: Futebol. Jogos Coletivos. Esporte.

\footnotetext{
*Grupo de Pesquisa em Comportamento Motor, Pontifícia Universidade Católica de Curitiba, Curitiba, PR, Brasil. E-mail: chip_vic33@yahoo.com.br

${ }^{\star *}$ Faculdade Adventista de Hortolândia-Curso de Educação Física/FAECH-UNASP. Hortolândia, SP, Brasil; Faculdade Network, Nova Odessa, SP, Brasil. E-mail: rsreverdito@gmail.com

***Universidade Federal do Paraná. Curitiba, PR, Brasil. E-mail: denisgreboggy@yahoo.com.br ****Pontifícia Universidade Católica de Curitiba. Curitiba, PR, Brasil. E-mail: carlos.afonso@pucpr.br

***** Faculdade de Ciências Aplicadas da Unicamp. Limeira, SP, Brasil. E-mail: alcides.scaglia@fca.unicamp.br
} 


\section{INTRODUÇÃO}

A primeira década do século XXI foi marcada por avanços significativos em múltiplos domínios do conhecimento aplicados ao futebol. Estes foram alavancados pelo desenvolvimento das ciências do esporte, as quais contribuíram para o aperfeiçoamento de materiais esportivos, para um melhor conhecimento do funcionamento do organismo humano e para o surgimento e aprimoramento de metodologias de ensino-aprendizagem aplicadas no processo de formação de jogadores em busca da excelência física e técnica (SMITH, 2003).

Tratando-se de metodologias de ensino-aprendizagem, observase que algumas delas apenas supervalorizam a formação e lapidação de verdadeiros "super-homens" e confundem os responsáveis pelo processo de formação de jogadores de futebol. Assim, muitos clubes não utilizam uma metodologia unificadora, tornando os departamentos de futebol de base em legítimos centros de miscelâneas de idéias (TEODORESCU, 1984; GARGANTA, 2002). Apesar da ciência poder promover novos caminhos para o esporte, muitos destes fogem da natureza primeiramente tática do futebol, e ainda são interpretados de forma redutora, analítica e arcaica (CANO MORENO, 2001; GARGANTA, 2001).

Um dos motivos que levam os clubes e treinadores aderirem às concepções convencionais é por serem de fácil compreensão, organização e aplicação, enquanto que a organização da tática do futebol requer mais perspicácia, tempo e criatividade (BANGSBO, 1994). O aprendizado tático é umas das chaves do processo de formação, uma vez observado os aspectos pedagógico-metodológicos adotados na prática, chega-se a uma conclusão: exercita-se muito e joga-se pouco e quase nada se compreende do jogar em equipe que o futebol exige constantemente (VICKERS, 2000; GRIFFIN; BUTLER, 2005). 
O presente artigo trata-se de um estudo bibliográfico de caráter reflexivo-propositivo, tem por objetivo apresentar os conteúdos para sustentação de um processo de ensino-aprendizagem, baseado na dimensão tática e na inter-relação de três preceitos fundamentais para o futebol: metodologia de treino (metodologia da compreensão tática), princípios de jogo e modelo de jogo.

\section{Metodologia da COMPREensão tática}

Há uma longa tradição no processo de ensino do futebol concentrada na dimensão física e técnica (HO, 2003). A conseqüência de um processo de ensino-aprendizagem pautado nesse modo é o fato dos jogadores acabarem compreendendo pouco sobre o jogo, reproduzindo apenas situações pré-determinadas pelo treinador (HO, 2003; MITCHELL; OSLIN; GRIFFIN, 2006).

Visando superar as concepções tradicionais, estudiosos dos jogos coletivos de invasão defendem que a dimensão tática seja o "norte" do processo (BAYER, 1994; GARGANTA, 1997; OLIVEIRA, 2004; LAGO, 2006). Para Gomes (2008) a dimensão tática deve ser entendida através da ótica da complexidade, dando coerência construtiva aos comportamentos e interações dos jogadores, conectando-os com as outras dimensões do jogo e desenvolvendo uma dinâmica coletiva. Desta forma, admite-se que o entendimento da natureza do futebol, tenha implicações relevantes quanto aos domínios do treino e do controle da evolução dos jogadores, influindo na concepção e na escolha dos procedimentos metodológicos adequados para o desenvolvimento de jogadores pensantes (BOTA; COLIBABA-EVULET, 2001; GARGANTA, 2007).

Outro fator que tem contribuído significativamente para a consolidação de novas propostas de ensino-aprendizagem é o avanço didático recente na pedagogia do esporte em relação ao uso de métodos (estratégias-metodologias), sistematização do conteúdo de ensino, instrumentos de avaliações, outras múltiplas possibilidades e 
significados atribuídos à prática esportiva. Aevolução das tendências ocorreu em função de subsídios trazidos das teorias: cognitivista (GRECO; BENDA, 1998; KRÖGER; ROTH, 2002), interacionista (FREIRE, 2003; PAES; BALBINO, 2005), ecológica (ARAÚJO; DAVIDS; HRISTOVSKI, 2006), complexa e sistêmica (BUNKER; THORPE, 1982; GARGANTA, 1997; SCAGLIA, 2003; REVERDITO; SCAGLIA, 2007).

As novas propostas teóricas foram fundamentadas em referenciais metodológicos: como o Teaching Games for Understanding (Ensinando o Jogo pela Compreensão), Teoria dos Jogos Desportivos Coletivos, Jogo Possível, Jogos Situacionais, Pedagogia das Intenções, etc. (MAÇÃ S; BRITO, 1998; MESQUITA; PEREIRA; GRAÇA, 2009; REVERDITO; SCAGLIA, 2009).

A abordagem para o ensino pela compreensão, sustentada pela tática do jogo e no entendimento crítico do contexto, pode ser classificada em três dimensões: utilizar um modelo de interação que restabeleça a composição transdimensional do jogo de futebol orientada pela dimensão tática, colocar o jogador em situação de resolução de problemas através da modificação e adaptação de jogos, a fim de desenvolver seu acervo de habilidades (tático-técnica, física, psicossociais e, o treinador com ajuda dos jogadores identificarem os problemas de jogo, da equipe e as soluções pedagógicas a serem tomadas (BUNKER; THORPE, 1982; MOMBAERTS, 1999; MITCHELL; OSLIN; GRIFFIN, 2006). Baseada no jogo e na resolução de seus problemas tem enquanto objetivos principais: o pensamento crítico, comunicação e a habilidade para resolver os problemas da equipe em conjunto, privilegiando a formação de jogadores autônomos, capazes de responder com um nível de eficácia diferenciado aos desafios que lhes vão surgindo. $O$ treinador é o agente mediador entre a forma de jogar construída e aquilo que precisa ser desenvolvido. Este deve promover situações para que os jogadores tenham liberdade na tomada de decisão e analisem os 
riscos e consequiências, tornando-os ativos no desenvolvimento da equipe, passando de reprodutores para construtores adjuntos das ações (WERNER; BUNKER; THORPE, 1996; GALLAGHER, 1997; STEPIEN; PIKE, 1997; CASARIN; OLIVEIRA, 2010). Deverá promover atividades desafiadoras, onde os problemas táticos são constantemente exigidos, de modo que a partir da estrutura complexa do jogo criem situações com tomadas de decisões contínuas, estimulando o pensamento criativo e a capacidade de avaliação dos jogadores, tanto na escala individual como na coletiva (BUNKER; THORPE, 1982; MITCHELL; OSLIN; GRIFFIN, 2006).

Para Kirk e MacPhail (2002) as experiências autênticas e significativas em situações de jogo promovem aprendizagem e motivação, pois os jogadores estão buscando soluções e não fazendo gestos obrigados e estereotipados.

A estruturação de jogos, modificando o tamanho dos espaços, número de jogadores, materiais, tamanho dos alvos (gols), duração das partidas, formas de pontuação, limitações qualitativas de algumas ações e zonas de condicionamentos permitem maiores possibilidades para a avaliação do jogo, resolução dos problemas e o desenvolvimento da criatividade (BUNKER; THORPE, 1982; GRIFFIN; MITCHELL; OSLIN, 1997; HOPPER; BELL, 2000). 


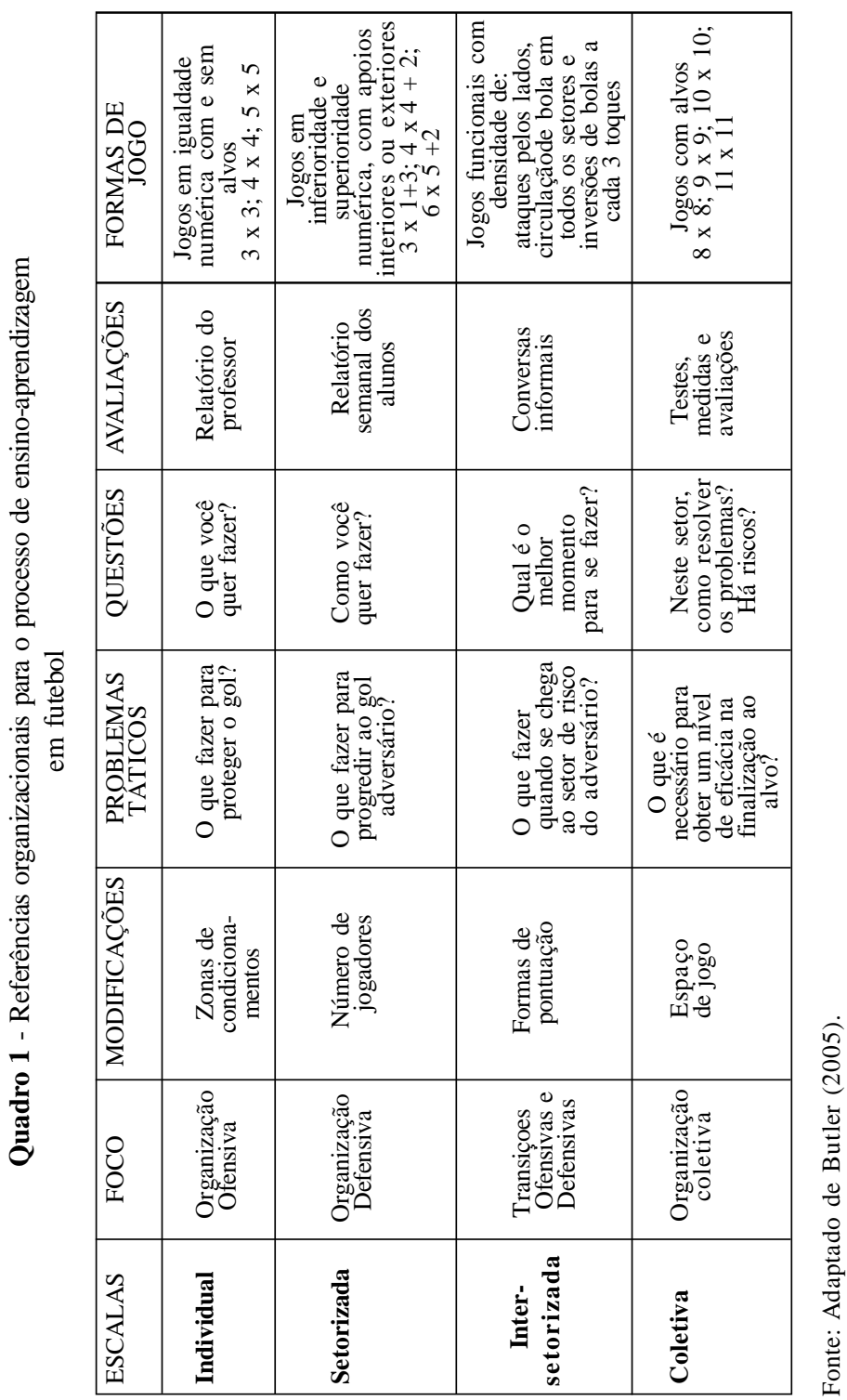


Segundo Garganta (2007), torna-se cada vez mais efetiva a tendência de compreender a "consciência tática do jogo", ficando claro que a metodologia eficaz para abordar o ensino-aprendizagem é a que reduz a complexidade do fenômeno (jogo) sem descurar a especificidade do confronto.

Segundo De Souza e Mitchell (2010) os constrangimentos impostos nos jogos estruturados propiciam aos jogadores estarem constantemente: avaliando, criando, prevendo e tomando decisões em relação às competências da equipe, com e sem a posse de bola, quer no ambiente de ensino-aprendizagem ou no jogo formal. A idéia de modificar o jogo em diversas formas e a progressão tática (aumento dos problemas táticos de acordo com o nível de discernimento) constitui-se como princípios pedagógicos fulcrais (GARGANTA, 2002; GRÉHAIGNER; WALLIAN; GODBOUT, 2005).

Evidencia-se que o processo de ensino-aprendizagem em futebol implica para os jovens jogadores: observar, extrair múltiplas informações pertinentes dos jogos modelados pelos professores, avaliar essas informações rapidamente e criticamente, a fim de reduzir o tempo necessário de sua análise, para posteriormente tomar a decisão (GRÉHAIGNER; GODBOUT; BOUTHIER, 2001).

\section{Princí́íos de JOGo}

O futebol apresenta-se como sequiências de situações problema que geram fluxos de comportamentos de contornos variáveis, organizados em torno de lógicas particulares, em função de regras e princípios (GARGANTA, 1997; 2007). Desta forma, o futebol consolida-se em uma complexa dimensão mais previsível, quando induzido por leis e princípios e com menor previsibilidade quando na materialização a partir da autonomia dos jogadores. Estes então fomentam a diversidade e a singularidade dos acontecimentos a partir do confronto entre sistemas concorrentes, caracterizados pela 
alternância de circunstâncias de: ordem e desordem, estabilidade, instabilidade, uniformidade e variedade (GARGANTA, 2007; LEONARDO; SCAGLIA; REVERDITO, 2009).

Tentando encontrar inteligibilidade nesta desordem e aleatoriedade pertencente ao futebol, Castelo (1996) salienta que os princípios se estabelecem como um quadro de referência para a organização do jogo, orientando o comportamento tático que visa a resolução eficaz dos diversos acontecimentos do mesmo.

Os princípios de jogo auxiliam a ação dos jogadores e são uma exigência natural do jogo (TEODORESCU,1984; BAYER,1994; GARGANTA, 1997; BOTA; COLIBABA-EVULET, 2001). Para Gomes (2008), estes nada mais são que referências (intencionais) do treinador e dos jogadores para solucionar os constantes problemas pertencentes ao jogo nos seus momentos de organização defensiva e ofensiva, bem como a transição defensiva e ofensiva.

$\mathrm{Na}$ concepção de Oliveira (2008), os princípios de jogo correspondem a padrões de comportamentos táticos evidenciados nas escalas coletiva inter-setorial, setorial e individual esperados pela equipe nos diferentes momentos do jogo. Os princípios definem-se como um conjunto de códigos que proporcionam possibilidades de atingirem rapidamente soluções táticas para os problemas advindos das situações com que se defrontam. Esse caráter organizativo constitui-se em alicerces para se jogar um futebol de qualidade (GARGANTA; PINTO, 1994; BOTA; COLIBABA-EVULET, 2001).

Para uma melhor compreensão didática, os princípios de jogo estão divididos em dois grupos: princípios globais (quadro 2) divididos em operacionais e fundamentais, constituindo referências funcionais comuns à todos os jogos coletivos de invasão para orientar a equipe ao cumprimento da lógica do jogo, e os princípios específicos (quadro 3) e seus conteúdos referentes aos diferentes e interconectados momentos do jogo. 
Quadro 2 - Princípios Globais

\begin{tabular}{lll}
\hline \multicolumn{2}{c}{ Princípios Operacionais } & \multicolumn{1}{c}{ Princípios Fundamentais } \\
\hline \multicolumn{1}{c}{ Ofensivos } & \multicolumn{1}{c}{ Defensivos } & \\
$\begin{array}{l}\text { Manter a posse de bola } \\
\text { Progredir o alvo adversário } \\
\text { Atacar o alvo adversário }\end{array}$ & $\begin{array}{l}\text { Recuperar a posse de bola } \\
\text { Impedir progres são ao alvo }\end{array}$ & $\begin{array}{l}\text { Recusar a inferioridade numérica } \\
\text { Evitar a igual dade numérica } \\
\text { Criar superioridade numérica }\end{array}$ \\
& & \\
\hline
\end{tabular}

Fonte: baseado em Bayer (1994) e Garganta e Pinto (1994).

Quadro 3 - Princípios Específicos

\begin{tabular}{|c|c|c|c|}
\hline \multicolumn{4}{|c|}{ PRINCIPIOS ESPECIFICOS (MOMENTOS DO JOGO) } \\
\hline Organização ofensiva & Transição Defensiva & Organização Defensiva & Transição Ofen siva \\
\hline $\begin{array}{l}\text { Circulação e posse de bola } \\
\text { Ataque di re to } \\
\text { Contra a taque } \\
\text { Largura } \\
\text { Profundidade } \\
\text { Mobilidade } \\
\text { Apoio } \\
\text { Penetr ação } \\
\text { Compactação ofensiva } \\
\text { Referências es paciais } \\
\text { (figuras geométricas) } \\
\text { Criação de espaços livres } \\
\text { Variabilidade de zonas de } \\
\text { finalização }\end{array}$ & $\begin{array}{l}\text { Pressão coletiva com coberturas } \\
\text { Pressão individualizada } \\
\text { Compactação } \\
\text { Retorno as linhas inicias de } \\
\text { marcação (tod a a equipe) } \\
\text { Retorno defen sivo orientado com } \\
\text { (pré-definidos) } \\
\text { Retorno defen sivo orientado com } \\
\text { trocas posi cionais } \\
\text { Faltas estratégicas } \\
\text { Equilíbri od efensivo }\end{array}$ & $\begin{array}{l}\text { Defesa zon a e zona pressing } \\
\text { Defesa indi vidual } \\
\text { Defesa Individual por setor } \\
\text { Defesa mi sta } \\
\text { Definição de bloco } \\
\text { Coordenação en tre as linhas } \\
\text { Comp actação defensiva } \\
\text { Coberturas } \\
\text { Contenção } \\
\text { Flutuação } \\
\text { Equilíbrio defensivo } \\
\text { Referências espaciais (figuras } \\
\text { geom étricas) } \\
\text { Direcionamento para zonas de } \\
\text { pressão }\end{array}$ & $\begin{array}{l}\text { Retirada da bola da zona de } \\
\text { pressão vertical com bola longa } \\
\text { Retirada da bola da zona de } \\
\text { pressão horizont al com bola } \\
\text { longa } \\
\text { Retirada da bola da zona de } \\
\text { pressão (hori zontal ou vertical) } \\
\text { Manuten ção da posse na zona } \\
\text { de recuperação direc ionada para } \\
\text { frente, trás ou lado. }\end{array}$ \\
\hline
\end{tabular}

Fonte: baseado em Bayer (1994) e Garganta e Pinto (1994).

É fundamental entender a hierarquização dos princípios de jogo em condições de perfeita articulação e congruência. Para Oliveira (2004) devem-se eleger nos momentos de organização defensiva e ofensiva, de transição defensiva e ofensiva, alguns princípios: (prioridades da equipe) em níveis de organização maiores e menores (grandes e médios princípios) e também se deve observar que os jogadores só conseguirão realizar determinados princípios corretamente se o compreenderem através dos jogos (metodologia de compreensão tática) e depois identificarem que realmente os princípios são: compatíveis com uma realidade, necessidade, entendimento individual e em equipe (OLIVEIRA, 2004; GOMES, 2008). 


\section{MODELOde JOGO}

A finalidade do modelo de jogo é proferir sentido ao desenvolvimento do processo em face de um conjunto de regularidades que se pretende observar, ou seja, delinear o caminho e os passos a serem dados. O modelo de jogo busca desenvolver um processo coerente e específico de treino, preocupado em criar uma determinada forma de jogar, orientada por padrões comportamentais (princípios de jogo) em seus quatro momentos: organização defensiva e ofensiva, transição defensiva e ofensiva (GARGANTA, 1997; OLIVEIRA, 2004; GOMES, 2008). No modelo de jogo devem constar os comportamentos dos jogadores nas diversas escalas, interconectados com a dimensão: técnica-física-psícologicaestratégica (TEODORESCU, 1984; BOTA; COLIBABAEVULET, 2001).

Para Gomes (2008), não existe um modelo de jogo único (universal), porque cada clube possui uma cultura de jogo e cada treinador, suas concepções e adaptações a essa cultura. Estes fatores determinam os objetivos comportamentais (princípios de jogo), particulares de cada equipe. A construção de um modelo de jogo deverá evidenciar uma propriedade fractal $^{1}$ única, aberta às contingências das interações entre os diferentes agentes (treinadores, jogadores, cultura), variando de acordo com cada clube (OLIVEIRA, 2004; TAMARIT, 2007; GOMES, 2008).

Quando culturas peculiares de clubes e conceitos de jogo de diferentes treinadores determinam as linhas gerais da organização do modelo de jogo, o processo de formação além de contemplar esses aspectos, deve também proporcionar diversos estímulos para os jovens se adaptarem às inúmeras adversidades do jogo (BOTA; COLIBABA-EVULET, 2001; PEÑAS; ACERO, 2005; TAMARIT,

\footnotetext{
'Uma propriedade fractal é capaz de fracturar e representar um modelo em sub modelos, existentes em várias escalas, que sejam representativos desse modelo, conseguindo representar o todo, independentemente da escala onde possa ser encontrado (MANDELBROT, 1998).
} 
2007). Neste contexto, o modelo de jogo não pode ser rígido, e sim variável e condizente a uma zona de desenvolvimento proximal $^{2}$ dos atletas, já que o cumprimento dos padrões comportamentais (princípios de jogo) poderão se diferenciar durante os anos de formação (OLIVEIRA, 2004), e também deve ser entendido como um sistema dinâmico que apresenta constante variabilidade para desenvolver criatividade dentro do mesmo e permitir aos potenciais talentos evoluírem para níveis de complexidade mais elevados, sem perda de identidade (OLIVEIRA, 2004; GOMES, 2008).

No processo de ensino-aprendizagem orientado pela construção de um determinado modelo de jogo deverá: passar pela observação e modelação de níveis de jogo diferenciados, do jogo elementar ao jogo de alto nível registrando as invariantes e singularidades estruturais e funcionais que os caracterizam, pela articulação dos diferenciados níveis de jogo, induzindo à evolução dos comportamentos e atitudes dos praticantes em consonância com os diferentes modelos (do principiante ao jogador de alto rendimento) (PINTO; GARGANTA, 1989; GARGANTA, 1997; GARGANTA, 2002).

$\mathrm{Na}$ seqüência apresentam-se três exemplos simplificados de modelos de jogo:

Quadro 4 - Modelo de jogo iniciante para idade de 11 à 13 anos

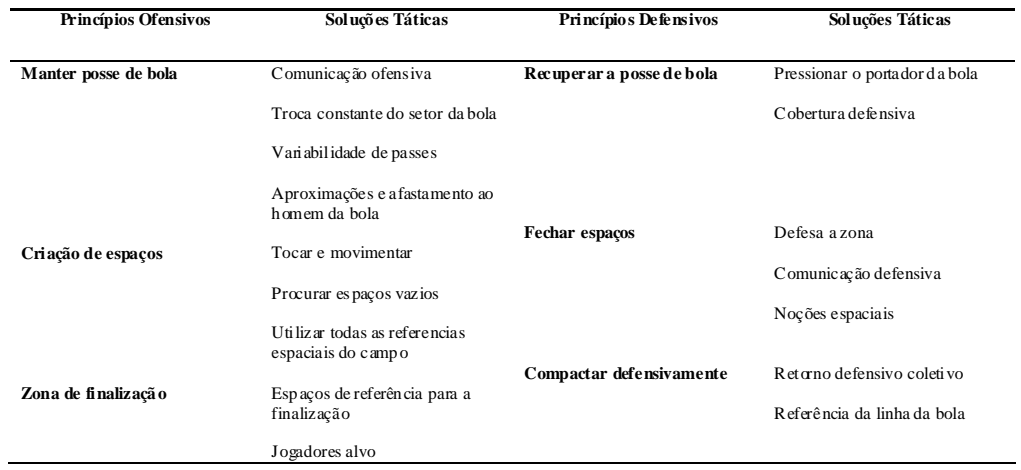

Fonte: adaptado de De Souza e Mitchell (2010).

${ }^{2}$ Usamos o conceito de Zona de Desenvolvimento Proximal (ZDP) proposto por Vygotsky (1991). 
Quadro 5 - Modelo de jogo regular, para idades entre 14 á 16 anos

\begin{tabular}{llll}
\hline \multicolumn{1}{c}{$\begin{array}{c}\text { Organização } \\
\text { Ofensiva }\end{array}$} & Transição Defensiva & $\begin{array}{c}\text { Organização } \\
\text { Defensiva }\end{array}$ & Transição Ofensiva \\
\hline Grandes Prinćpios & Grandes Princípios & Grandes Princípios & Grandes Princípios \\
Ataque rápi do & $\begin{array}{l}\text { Temporização } \\
\text { defensiva }\end{array}$ & Marcação Zonal & $\begin{array}{l}\text { Tirar a bola da zona de } \\
\text { pressão }\end{array}$ \\
Contra-ataque & Médios Princípios & Médios Princípios & Médios Princípios \\
$\begin{array}{l}\text { Utilizar um homem de } \\
\text { referência }\end{array}$ & $\begin{array}{l}\text { Noção espacial de } \\
\text { largura e profundidade }\end{array}$ & Flutuação & $\begin{array}{l}\text { Lançamentos } \\
\text { Verticais e Diagonais }\end{array}$ \\
$\begin{array}{l}\text { Utilizar dois homens } \\
\text { estrategicamente } \\
\text { próximos a bola }\end{array}$ & $\begin{array}{l}\text { Compactação entre as } \\
\text { linhas de marcação }\end{array}$ & Dobertura & $\begin{array}{l}\text { Zonas de referências } \\
\text { para a disputa da bola }\end{array}$ \\
\hline
\end{tabular}

Fonte: adaptado de Casarin e Esteves (2010).

O modelo de jogo do Quadro 5, pode se caracterizar para idades mais inferiores em termos cronológicos. Sua aplicabilidade é viável no infantil e juvenil por exemplo. Entretanto o modelo de jogo apresentado no Quadro 6, apresenta-se mais avançado, justamente por apresentar características mais complexas, sendo assim sua possível aplicação nas categorias semi-profissionais e até mesmo em equipes de alto-rendimento.

Quadro 6 - Modelo de jogo avançado para idades entre 17 à 20 anos

\begin{tabular}{llll}
\hline \multicolumn{1}{c}{$\begin{array}{c}\text { Organização } \\
\text { Ofensiva }\end{array}$} & Transição Defensiva & \multicolumn{1}{c}{$\begin{array}{c}\text { Organização } \\
\text { Defensiva }\end{array}$} & Transição Ofensiva \\
\hline Grandes Princípios & Grandes Princípios & Grandes Princípios & Grandes Princípios \\
$\begin{array}{l}\text { Circul ação e Posse de } \\
\text { Bola }\end{array}$ & $\begin{array}{l}\text { Pressão coletiva na } \\
\text { perda da posse de bola }\end{array}$ & Zona Pressing & $\begin{array}{l}\text { Retirar a bola da } \\
\text { zona de pres são }\end{array}$ \\
Médios Princípios & Médios Princípios & Médios Princípios & Médios Princípios \\
Mobilidade & $\begin{array}{l}\text { Encurtamento das } \\
\text { linhas de passe }\end{array}$ & $\begin{array}{l}\text { Pressão coletiva em } \\
\text { todos setores do campo }\end{array}$ & $\begin{array}{l}\text { Retirar a bola } \\
\text { em largura }\end{array}$ \\
Apoio & $\begin{array}{l}\text { Rápida } \\
\text { Compactação }\end{array}$ & Cobertura & $\begin{array}{l}\text { Utilizar passes } \\
\text { curtos e rápidos }\end{array}$ \\
$\begin{array}{l}\text { Formação de figuras } \\
\text { geométricas }\end{array}$ & Dobras & $\begin{array}{l}\text { Manter a posse de } \\
\text { bola }\end{array}$ \\
\hline
\end{tabular}

Fonte: adaptado de Casarin e Esteves (2010). 
Modelar um sistema dinâmico (futebol) significa mapear não apenas os seus comportamentos (princípios de jogo), e sim também as variáveis que emergem da interação e inter-relação dos executantes (treinadores-jogadores, companheiros-companheiros, companheiros-adversários) e entender o jogo como inteireza inquebrantável mesmo dividindo-o didaticamente em momentos, para uma melhor compreensão do modelo de jogo (GARGANTA, 2002; GARGANTA, 2007). Esse processo suscita jogadores mais inteligentes, sistemáticos e, acima de tudo, libertos para elegerem os melhores caminhos para suas ações. Essa "liberdade" (entenda-se por autonomia consciente) deve estar presente em todo o processo de formação, ou seja, o jogador atuará de acordo com determinado modelo, mas seu grau de liberdade para "criar" não será afetado (TAMARIT, 2007; GOMES, 2008). Portanto, busca-se no processo de ensino-aprendizagem orientado pelos princípios do jogo, construir um modelo de jogo, para compreensão e resolução dos problemas próprios ao contexto do jogo, valorizar e respeitar a riqueza de ações que emergem e a capacidade do jogador de responder às suas emergências, enquanto sujeito detentor de inteligência criadora (MARINA, 1995).

\section{Considerações finaIS}

O objetivo central desse artigo foi orientado pela necessidade de fornecer subsídios para: pesquisadores, professores de Educação Física e treinadores envolvidos no processo de formação e ensino/ aprendizagem do futebol, que desafie os jogadores a resolverem problemas de ordem tática, conceber uma filosofia orientadora para o processo de ensino-aprendizagem baseado nos pressupostos da complexidade, na articulação de seguintes níveis: metodologia da compreensão tática, princípios de jogo e modelo de jogo, que interligados e inter-relacionados, propiciam um grande aprofundamento, abertura para novas idéias e uma ruptura ideológica e paradigmática dos procedimentos pedagógico-metodológicos acerca do futebol. 


\section{ArtigosOriginais}

Mostraram-se nesse estudo os conteúdos que cercam a organização do processo de ensino-aprendizagem, baseado em situações jogadas (realidade e complexidade de jogo) e condicionadas pela modificação de alguns parâmetros específicos (metodologia de devidamente pautado em princípios, sustentando sua identidade, fornecendo indicações acerca dos conteúdos e do processo de ensino-aprendizagem.

Espera-se que esta abordagem proporcione novos insights sobre o processo de ensino-aprendizagem, o pensar crítico sobre a forma de planejar, treinar, atuar e intervir, construindo novos saberes para a pedagogia do esporte. 
Model and Play Soccer in the Process of Education: global and specific principles

Abstract: The tactical dimension must be understood like a soccer teaching and learning center, taking an organized character, interdependency, intentionality and conscious. This article was focused in concepts and content to support a teaching-learning process, based on tactical and interdependence dimension about three basics aspects: the tactical understand methodology, the game principles and game models. At this article was also described and suggested specifics game principles and game models for different groups of youth people, which are composed by common peculiarities to team invasion sports, and own of the game culture.

Keywords: Soccer. Team Games. Sports.

Modelo de juego y proceso de enseñanza en el fútbol: principios generales y específicos

Resumen: La dimensión táctica debe ser comprendida como un centro de enseñanza y aprendizaje en el fútbol, teniendo su organización del carácter multidimensional, intencional y consciente. Este artículo se centra en la presentación de conceptos y contenidos para apoyar la enseñanza y aprendizaje basado en la dimensión táctica y por la interdependencia de los tres aspectos fundamentales: una metodología para la comprensión táctica del fútbol, por los principios y modelos del juego. Fueron descritos y sugeridos principios y modelos específicos del juego de fútbol, apartados por grupos de edad diferentes, que se componen de rasgos comunes a los deportes colectivos de invasión, y la cultura propia del juego.

Palabras clave: Fútbol. Juegos Colectivos. Deportes. 


\section{REFERÊNCIAS}

ARAÚJO, D.; DAVIDS, K.; HRISTOVSKI, R. The ecological dynamics of decision making in sport. Psychology of Sport and Exercise, Loughborough, v. 7, n. 6, p. 653-676, 2006.

BANGSBO, J. Energy demands in competitive soccer. Journal of Sports Sciences, London, v.12, p. 5-12, 1994.

BAYER, C. O ensino dos desportos coletivos. Paris: Vigot, 1994.

BENTO, J. O. Formação e desporto. In:TANI, G.; BENTO, J. O.; PETERSEN, R. D. S. Pedagogia do Desporto. Rio de Janeiro: Guanabara Koogan, 2006, p. 41-57.

BOTA, I.; COLIBABA -EVULET, D. Jogos desportivos coletivos: teoria e metodologia. Lisboa: Instituto Piaget, 2001.

BUTLER, J. The Reflection \& Projection on TGFU From North America's Perspective. 2005. Disponível em: <http://www.tgfu.org/The\%20Reflection\% 20 and\%20Projection\%20on\%20TGfU\%20from\%20North\%204.pdf>. Acesso em: 20 ago. 2010.

BUNKER, D.; THORPE, R. A model for the teaching of games in the secondary school. Bulletin of Physical Education, Driffield ,v. 10, p. 9-16, 1982.

CANO MORENO, O. Entrenamiento global basado en la interpretación del juego. Sevilla: Wanceulen, 2001.

CASARIN, R. V.; ESTEVES, L. A. S. Para ganhar no futebol precisa-se treinar, mas o que treinar? Lecturas, Educación y Deportes, Revista Digital, Buenos Aires, v.14, n. 142, 2010. Disponível em: http://www.efdeportes.com/efd144/periodizacaotactica-sua-aplicacao-no-futebol.htm. Acesso em: 20 ago. 2010.

CASARIN, R. V.; OLIVEIRA, R. Periodização táctica: princípios estruturantes e erros metodológicos na sua aplicação no futebol. Lecturas, Educación y Deportes, Revista Digital, Buenos Aires, v. 15, n. 144, 2010. Disponível em: http:/ /www.efdeportes.com/efd144/periodizacao-tactica-sua-aplicacao-no-futebol.htm. Acesso em: 25 ago. 2010.

CASTELO, J. Futebol, a organização do jogo. Lisboa: Edição do autor, 1996.

CASTELO, J. Modelo de Jogo. Fútbol Táctico, Madrid, n. 18, p.1-9, 2008. Disponível em <http://www.futbol-tactico.com/futbol/articulo.php?idedi=19\&cat=5\&id=271>. Acesso em: 12 set. 2010.

DE SOUZA.; MITCHELL, S. TGfU as a Coaching Methodology. In: J. BUTLER.; L. GRIFFIN (Eds.). More Teaching Games for Understanding, Theory Research and Practice. Champaign: Human Kinetics, 2010. 
FREIRE, J. B. Pedagogia do futebol. Campinas: Autores Associados, 2003.

GALLAGHER, S. A. Problem-based learning: Where did it come from, what does it do, and where is it going? Journal for the Education of the Gifted, Muncie, $v$. 20, n. 4, p. 332-362, 1997.

GARGANTA, J. Modelação táctica do jogo de Futebol: estudo da organização da fase ofensiva em equipas de alto rendimento. 1997. 325f. Tese (Doutorado em Educação Física)- FCDEF- Universidade do Porto, 1997.

GARGANTA, J. A análise da performance nos jogos desportivos. Revisão acerca da análise do jogo. Revista Portuguesa de Ciências do Desporto, Porto, v. 1, n. 57, p.57-64, 2001.

GARGANTA, J. Competência de ensino de jovens futebolistas. Lecturas, Educación y Deportes, Revista Digital, Buenos Aires, v.8, n. 45, 2002. Disponível em: <http://www.efdeportes.com/efd45/ensino.htm>. Acesso em: 13 ago. 2010.

GARGANTA, J. Modelação táctica em jogos desportivos: a desejável cumplicidade entre pesquisa, treino e competição. In: TAVARES, F.; GRAÇA, A.; GARGANTA, J. (Eds.). Proceedings do $1^{\circ}$ Congresso Internacional de Jogos Desportivos, 2007, Porto: Faculdade de Desporto da Universidade do Porto e Centro de Estudos dos Jogos Desportivos, 2007.

GARGANTA, J.; PINTO, J. O ensino do futebol. In: GRAÇA, A.; OLIVEIRA, J. (Ed.). O ensino dos jogos desportivos. Porto: Centro de Estudos dos Jogos Desportivos, FCDEF-UP, 1994, p. 97-137.

GOMES, M. O desenvolvimento do jogar segundo a periodização táctica. Madrid: MCSports, 2008.

GRECO, P. J.; BENDA, R. N. (Org.) Iniciação Esportiva Universal: da aprendizagem motora ao treinamento técnico. Belo Horizonte: UFMG, 1998.

GRÉHAIGNE, J. F.; WALLIAN, N.; GODBOUT, P. Tactical-decision learning model and students' practices. Physical Education and Sport Pedagogy, Loughborough, v. 10, n. 3, p. 255-269, 2005.

GRÉHAIGNE, J.; GODBOUT, P.; BOUTHIER, D. The teaching and learning of decision making in team sports. Quest, Champaign, n. 53, p. 59-76, 2001.

GRIFFIN, L. L.; MITCHELL, S. A.; OSLIN, J. L. Teaching sport concepts and skills: a tactical games approach. Champaign, IL: Human Kinetics, 1997.

GRIFFIN, L.; BUTLER, J. Teaching Games for Understanding: theory, research and practice. Illinois: Human Kinetics, 2005. 
HO, W. Teaching games for understanding - model rethinking from the integrated perspective. In: Light, R.; SWABEY, K.; BROOKER, R. (Eds.). Teaching Sport and Physical Education for Understanding. Melbourne: University of Melbourne, Melbourne, 2003.

HOPPER, T.; BELL, R. A tactical framework for teaching games: Teaching strategic understanding and tactical awareness. Physical and Health Education Journal, Ottawa, v. 66, n. 4, p. 14-19, 2000.

KIRK, D.; MACPHAIL, A. Teaching games for understanding and situated learning: Rethinking the Bunker - Thorpe model. Journal of Teaching in Physical Education, Champaign, v. 21, n. 2, p. 177-192, 2002.

KRÖGER, C.; ROTH, K. Escola da bola: um ABC para iniciantes nos jogos esportivos. São Paulo: Phorte, 2002.

LAGO, C. El análisis del rendimiento en los deportes de equipo. Algunas consideraciones metodológicas. Actas del IV Congreso de la Asociación Española de Ciencias del Deporte, A Coruña, 115-120, A Coruña, 2006.

LEONARDO, L.; SCAGLIA, A. J.; REVERDITO, R. S. O ensino dos esportes coletivos: metodologia pautada na família dos jogos. Motriz, Rio Claro, v. 15, n. 2, p. 236-246, 2009.

MAÇÃS, V.; BRITO, J. A decisão técnico-táctica no jogador de Futebol. Horizonte, Lisboa, v. 81, p 12-16, 1998.

MANDELBROT, B. Objectos fractais: forma, acaso e dimensão. Lisboa: Gradiva, 1998.

MARINA, J. A. Teoria da inteligência criadora. Lisboa: Editorial Caminho, 1995.

MESQUITA, I.; PEREIRA, F.; GRAÇA, A. 2009 . Modelos de ensino dos jogos desportivos: investigação e ilações para a prática. Motriz, Rio Claro, v. 15, n. 4, p. 944-954, 2009. Disponível: <http://cecemca.rc.unesp.br/ojs/index.php/motriz/article/ view/2562/2687>. Acesso em: 12 ago. 2010.

MITCHELL, S.A.; OSLIN, J.L.; GRIFFIN, L.L. Teaching sport concepts and skills: A Tactical games approach. Champaign, IL: Human Kinetics, 2006.

MOMBAERTS, E. Fútbol: del análisis del juego a la formación del jugador. Barcelona: INDE, 1999.

OLIVEIRA, J. G. Conhecimento Específico em Futebol. Contributos para a definição de uma matriz dinâmica do processo de ensino-aprendizagem/treino do jogo. 2004. 214f. Dissertação (Mestrado Ciência do Desporto) - Faculdade de Ciências do Desporto, Universidade do Porto, 2004. 
OLIVEIRA, J. G. O Processo de Construção de um Modelo de Jogo de uma Equipa de Futebol. In Documento orientador: sessão teórica. Curso de Treinadores - Nível I da Associação de Futebol do Porto. Póvoa de Varzim. 2008. < http:// www.afporto.com/afporto/index.html >. Acesso em: 15 ago. 2010.

PAES, R. R.; BALBINO, H. F. Processo de ensino e aprendizagem do basquetebol: perspectivas pedagógicas. In: ROSE JÚNIOR, D.; TRICOLI, V. (Org.). Basquetebol: uma visão integrada entre ciências e prática. Barueri: Manole, 2005.

PINTO, J.; GARGANTA, J. Futebol português: Importância do modelo de jogo no seu desenvolvimento. Horizonte, Lisboa, v. 33, n. 5, p. 94-98, 1989.

PEÑAS, C. L.; ACERO, R. M. Complejidad y dificultad de estudio en los deportes de equipo: las tuercas y tornillos del juego. 2005. Disponível em: <http:// www.praxiologiamotriz.inefc.es/PDF/seminario_IX_carlos.pdf>. Acesso em: 22 ago. 2010.

REVERDITO, R. S.; SCAGLIA, A. J. A gestão do processo organizacional do jogo: uma proposta metodológica para o ensino dos jogos coletivos. Motriz, Rio Claro, v. 13, n. 1, p. 51-63, 2007. Disponível em: <http://cecemca.rc.unesp.br/ojs/index.php/ motriz/article/view/256/742>. Acesso em: 21 jul. 2010.

SCAGLIA, A. J. O Futebol e o Jogo/Brincadeira de Bola com os Pés: todos semelhantes, todos diferentes. 2003. 164f. Tese (Doutorado em Educação Física)

- Faculdade de Educação Física, Universidade Estadual de Campinas, 2003.

SMITH, D. A framework for understanding the training process leading to elite performance. Sports Medicine, Londres, v. 33 n.15, p. 1103-1126, 2003.

STEPIEN, W. J.; PIKE, S. L. Designing problem-based learning units. Journal for the Education of the Gifted, Muncie, v. 20, n. 4, p. 380-400, 1997.

VICKERS, J. Decision Training: A new approach to coaching. In: Coaches Association of British Columbia, 2000. Disponível em: <http://www.coaches.bc.ca/ pdfs/documents/intro\%20for\%20dt\%20handbook.pdf>. Acesso em: 20 ago. 2010.

VIGOTSKY, L. S. A formação social da mente: o desenvolvimento dos processos psicológicos superiores. São Paulo: Martins Fontes, 1991.

TAMARIT, X. Que es la "Periodización Táctica"? Vivenciar el "juego" para condicionar el Juego. Madrid: MCSports, 2007.

TEODORESCU, L. Problemas da teoria e metodologia nos jogos desportivos. Lisboa: Livros Horizonte, 1984. 


\section{ArtigosOriginais}

WERNER, P.; THORPE, R.; BUNKER, D. Teaching games for understanding: evolution of a model. The Journal of Physical Education, Recreation \& Dance, Ohio, v. 67, n. 1, 28-33, 1996.

Endereço para correspondência:

Rodrigo Vicenzi Casarin

Rua:15 de Novembro

Cidade: Nova Erechim

Estado: Santa Catarina

CEP:89865-000

e-mail: chip_vic33@yahoo.com.br

Recebido em: 18.09.2010

Aprovado em: 18.04.2011 
